\title{
Ozone decomposition on Saharan dust: an experimental investigation
}

\author{
F. Hanisch and J. N. Crowley \\ Max-Planck-Institut für Chemie, Division of Atmospheric Chemistry, Postfach 3060, 55020 Mainz, Germany \\ Received: 19 August 2002 - Published in Atmos. Chem. Phys. Discuss.: 5 November 2003 \\ Revised: 24 January 2003 - Accepted: 27 January 2003 - Published: 11 February 2003
}

\begin{abstract}
The heterogeneous reaction between $\mathrm{O}_{3}$ and authentic Saharan dust surfaces was investigated in a Knudsen reactor at $\approx 296 \mathrm{~K}$. O 3 was destroyed on the dust surface and $\mathrm{O}_{2}$ was formed with conversion efficiencies of 1.0 and 1.3 molecules $\mathrm{O}_{2}$ per $\mathrm{O}_{3}$ molecule destroyed for unheated and heated samples, respectively. No $\mathrm{O}_{3}$ desorbed from exposed dust samples, showing that the uptake was irreversible. The uptake coefficients for the irreversible destruction of $\mathrm{O}_{3}$ on (unheated) Saharan dust surfaces depended on the $\mathrm{O}_{3}$ concentration and varied between $3.5 \times 10^{-4}$ and $5.5 \times 10^{-6}$ for the initial uptake coefficient $\left(\gamma_{0} \approx 3 \times 10^{-5}\right.$ at $30 \mathrm{ppbv}$ $\mathrm{O}_{3}$ STP) and between $4.8 \times 10^{-5}$ and $2.2 \times 10^{-6}$ for the steady-state uptake coefficient $\left(\gamma_{s s} \approx 7 \times 10^{-6}\right.$ at $30 \mathrm{ppbv}$ $\mathrm{O}_{3}$ STP). At very high $\mathrm{O}_{3}$ concentrations the surface was deactivated, and $\mathrm{O}_{3}$ uptake ceased after a certain exposure period. Sample re-activation (i.e. de-passivation) was found to occur over periods of hours, after exposure to $\mathrm{O}_{3}$ had ceased, suggesting that re-activation processes play a role both in the laboratory and in the atmosphere.
\end{abstract}

\section{Introduction}

Between 1600 and $2000 \mathrm{Tg}$ of mineral aerosol are predicted to be uplifted annually into the atmosphere (Ginoux et al., 2001). The major source areas of the world are situated in a broad band that extends from the west coast of North Africa, across the Arabian Peninsula to central Asia, approximately in the $10^{\circ} \mathrm{N}-28^{\circ} \mathrm{N}$ latitude band (e.g. Prospero, 1999). Mineral aerosol is uplifted from so-called "hot spots" (Gillette, 1999) into the atmosphere by strong surface winds that travel behind cold frontal systems (Carmichael et al., 1996). Particles smaller than $10 \mu \mathrm{m}$ have atmospheric lifetimes of several days (Prospero, 1999) and can be transported over thou-

Correspondence to: J. N. Crowley

(crowley@mpch-mainz.mpg.de) sands of kilometres across the N. Atlantic and the N. Pacific (Duce et al., 1980; Savoie and Prospero, 1982), travelling mainly at heights between 3 and $7 \mathrm{~km}$ (Prospero et al., 1981; Husar et al., 1997).

Mineral dust is frequently associated with nitrate and sulphate, the concentrations of which can increase with transport time (e.g. Savoie and Prospero, 1982; Savoie et al., 1987; Prospero and Savoie, 1989; Okada et al., 1990), implying that mineral aerosol may provide a reactive surface able to support heterogeneous processing of trace gases. Early modelling studies (Zhang et al., 1994; Dentener et al., 1996) have considered the possibility that mineral aerosol can influence the tropospheric budgets of important trace gases $\left(\mathrm{O}_{3}\right.$, $\mathrm{NO}_{\mathrm{y}}, \mathrm{HO}_{\mathrm{y}}$ ), and identified the potential role of mineral dust in modifying photochemical cycles on a global scale. Recently, field observations of reduced $\mathrm{O}_{3}$ concentrations in a mineral aerosol plume were interpreted as resulting from direct uptake of $\mathrm{O}_{3}$ on the dust particle surface (50\%) with the rest resulting from changes in $\mathrm{NO}_{\mathrm{y}}$ (de Reus et al., 2000).

The catalytic destruction of $\mathrm{O}_{3}$ has been subject of scientific interest for more than 40 years because of its toxicity (Ouederni et al., 1996; Dhandapani and Oyama, 1997). A number of studies have been performed on the adsorption of $\mathrm{O}_{3}$ onto various mineral oxides, using electron paramagnetic resonance, infrared spectroscopy and kinetic measurement techniques (Dhandapani and Oyama, 1997). The surfaces examined were among others: $\gamma-\mathrm{Al}_{2} \mathrm{O}_{3}$ (Klimovskii et al., 1983; Bulanin et al., 1995a; Thomas et al., 1997), $\mathrm{SiO}_{2}$ (Bulanin et al., 1994), $\mathrm{TiO}_{2}$ (Bulanin et al., 1995a, 1995b), $\mathrm{CaO}$ (Bulanin et al., 1997) and $\mathrm{MgO}$ (Bulanin et al., 1995a; Berlier et al., 2002). A few semi-quanitative studies on the interaction between ozone and authentic mineral dust have been published (Suzuki et al., 1979; Alebic-Juretic et al., 1992; Alebic-Juretic et al., 2000), and initial uptake coefficients for $\mathrm{O}_{3}$ uptake onto synthetic and authentic minerals have been measured (Michel et al., 2002).

The interaction of ozone with mineral dust is also impor- 
Table 1. Knudsen reactor parameters

\begin{tabular}{lll}
\hline Knudsen reactor parameter & \multicolumn{2}{c}{ Value } \\
\hline volume & $V$ & $120 \mathrm{~cm}^{3}$ \\
temperature & $T$ & $296 \mathrm{~K}$ \\
total pressure & $p$ & $<1 \mathrm{mTorr}$ \\
$\mathrm{O}_{3}$ number density & & $3.1 \times 10^{10}$ to $1.7 \times 10^{13} \mathrm{~cm}^{-3}$ \\
$\mathrm{O}_{3}$ flow & & $3.0 \times 10^{12}$ to $1.7 \times 10^{15} \mathrm{~s}^{-1}$ \\
escape orifice diameter & $d$ & $3.5 \mathrm{~mm}$ \\
escape orifice escape rate & $k_{\text {esc }}$ & $0.3257(\mathrm{~T} / \mathrm{M})^{1 / 2} \mathrm{~s}^{-1 *}$ \\
surface area of sample support & $A_{S}$ & 1.0 and $2.25 \mathrm{~cm}^{2}$ \\
$\mathrm{O}_{3}$ sample collision frequency & $\omega$ & 75.5 and $170.0 \mathrm{~s}^{-1}$ \\
\hline
\end{tabular}

* $T$ in $\mathrm{K}, M$ in atomic mass units

tant in the context of chemical ageing or activation of the surface which could modify the heterogeneous behaviour of other trace gases. In the present study we examine experimentally a number of aspects of the interaction of $\mathrm{O}_{3}$ with Saharan dust surfaces.

\section{Experimental section}

The experimental set-up has been described in detail before (Hanisch and Crowley, 2001), and only salient features and modifications are reproduced here. The gas-mixing facility, Knudsen reactor and mass spectrometer are shown schematically in Fig. 1.

\subsection{Knudsen reactor / mass spectrometer}

The stainless steel Knudsen reactor consists of a main compartment and a sample compartment $(296<\mathrm{T} / \mathrm{K}<450)$ which can be separated by an isolation plate. All interior parts and walls of the Knudsen reactor are coated with Teflon (DuPont FEP 121-A). The total volume, including the connections to the mass spectrometer (MS) and to the pressure gauge (0.01-100 mTorr; 1 Torr corresponds to $1.333 \mathrm{hPa}$ ), is $120 \mathrm{~cm}^{3}$. The volume of the sample compartment is just $2.45 \mathrm{~cm}^{3}$ which reduces artefacts caused by changes in the Knudsen reactor volume after the isolation plate is opened. The main compartment of the Knudsen reactor is coupled to the MS via a variable diameter escape orifice. In the present experiments a $3.5 \mathrm{~mm}$ diameter orifice was used. Before entering the MS, the molecular beam was modulated by a punched wheel chopper at $244 \mathrm{~Hz}$, permitting phasesensitive detection. The molecular beam was ionised with a cross-beam rhenium ion source, and ions were mass selected with a quadrupole analyser and detected with a secondary electron multiplier. The escape rate constants $k_{\text {esc }}$ for the species involved were calculated from the mass and temperature dependent expression presented in a previous publica-

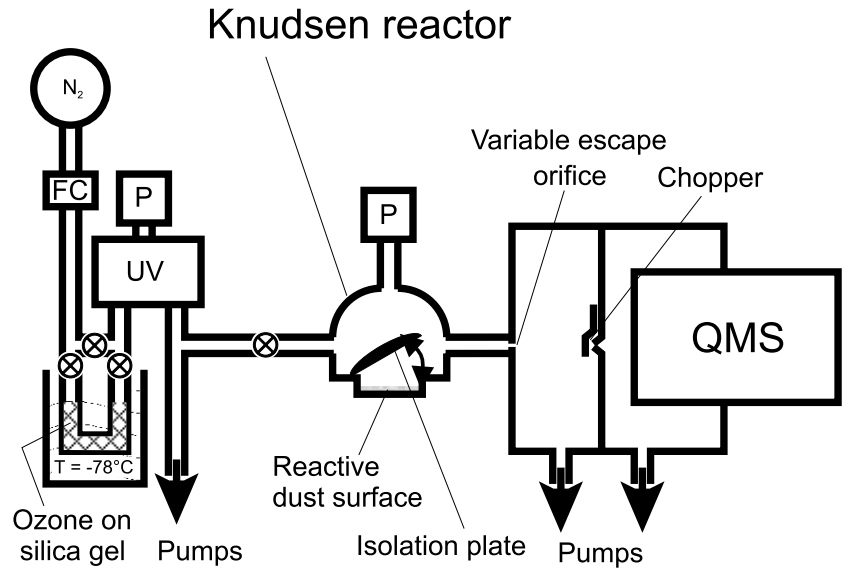

Fig. 1. Schematic diagram of the experimental set-up including Knudsen reactor, quadrupole mass spectrometer (QMS), pressure gauges (P), UV absorption facility (UV), and mixing line with flow controllers (FC). The pressure in the Knudsen reactor was generally $<1 \mathrm{mTorr}$, the pressure in the mixing line about 5 Torr, and the pressure in the mass spectrometer chamber about $10^{-6}$ Torr.

tion (Hanisch and Crowley, 2001). They are listed in Table 1, together with other relevant Knudsen reactor parameters.

\subsection{Reactant gas preparation}

Ozone, generated with a commercial ozone generator and stored on silica gel in a U-tube at dry ice temperature, was transported to the Knudsen reactor in a variable nitrogen eluent flow, and its concentration was monitored directly by UV absorption at $254 \mathrm{~nm}$ over a $1 \mathrm{~cm}$ path length.

\subsection{Dust sample characterisation and preparation}

The Saharan dust used in these experiments originates from the Cape Verde Islands (SDCV). The composition of SDCV, as determined by energy dispersive $\mathrm{X}$-ray spectroscopy, is given in Table 2. The SDCV samples were prepared by mixing between 2.3 and $96.4 \mathrm{mg}$ of dust into a paste with ethanol or water and dispersed on polished $\alpha-\mathrm{Al}_{2} \mathrm{O}_{3}(11 \overline{2} 0)$ single crystals (surface area $1.0 \mathrm{~cm}^{2}$ or $2.25 \mathrm{~cm}^{2}$; MaTecK, Jülich, Germany), which were placed in the sample compartment and left under vacuum ( $p \sim 2 \times 10^{-6}$ Torr) for 2 to $20 \mathrm{~h}$. Some of the samples were additionally heated to $\approx 450 \mathrm{~K}$ for $5 \mathrm{~h}$ under vacuum. When referring to sample masses, we always normalise to an area of $1 \mathrm{~cm}^{2}$ in order to make measurements of uptake coefficients, using the two sample supports, comparable.

The density of single SDCV particles (averaged over an ensemble) was measured with a Helium pyknometer (Micrometrics AccuPyk 1330). We refer to this as the "true density". The bulk density of the substrate was not determined for each sample used to measure $\mathrm{O}_{3}$ uptake, but derived in separate experiments in which larger amounts of dust were 
Table 2. Composition of SDCV, as determined with energy dispersive X-ray spectroscopy

\begin{tabular}{cc}
\hline Compound & $\%$ \\
\hline $\mathrm{Na}_{2} \mathrm{O}$ & 2.1 \\
$\mathrm{MgO}$ & 5.1 \\
$\mathrm{Al}_{2} \mathrm{O}_{3}$ & 17.6 \\
$\mathrm{SiO}_{2}$ & 47.1 \\
$\mathrm{P}_{2} \mathrm{O}_{5}$ & 0.6 \\
$\mathrm{SO}_{3}$ & 0.3 \\
$\mathrm{~K}_{2} \mathrm{O}$ & 2.5 \\
$\mathrm{CaO}$ & 5.0 \\
$\mathrm{TiO}$ & 4.5 \\
$\mathrm{MnO}$ & $(0.3)$ \\
$\mathrm{FeO}$ & 14.7 \\
\hline
\end{tabular}

used (ca. $1 \mathrm{~g}$ ), for which the sample volume could be precisely determined using a calibrated cylinder. Measurements of bulk density were frequently undertaken to investigate the reproducibility of the procedure, which was found to be better than $\pm 10 \%$. For dust samples used in the uptake experiments (typically $5-50 \mathrm{mg}$ ) the sample height could not be determined in this way with sufficient precision, and was derived from the bulk density, and the geometry of the sample holder. The assumption inherent to this procedure is that the light samples have the same bulk density as the heavy ones. The average particle diameter was determined with a Palas Particle Counter Sizer 2010, and the BET surface areas were measured with a Quantachrome Autosorb 6B.

\subsection{Measurement procedure and data analysis}

Uptake coefficients, $\gamma$, were determined in continuous flow experiments at room temperature $(296 \mathrm{~K})$. The pressure, $p$, inside the Knudsen reactor was less than 1 mTorr, i.e. the experiments were performed in the molecular flow regime. The $\mathrm{O}_{3}$ concentration inside the Knudsen reactor was systematically varied between $3.1 \times 10^{10} \mathrm{~cm}^{-3}$ and $1.7 \times 10^{13} \mathrm{~cm}^{-3}$. The corresponding $\mathrm{O}_{3}$ flows through the Knudsen reactor into the MS were between $3.0 \times 10^{12} \mathrm{~s}^{-1}$ and $1.7 \times 10^{15} \mathrm{~s}^{-1}$ $\left(F_{\mathrm{O}_{3}}=97.28 \mathrm{~cm}^{3} \mathrm{~s}^{-1} \times\left[\mathrm{O}_{3}\right]\right) . \mathrm{O}_{3}$ was monitored by the mass spectrometer at $m / z=48\left(\mathrm{O}_{3}^{+}\right)$and $\mathrm{O}_{2}$ at $\mathrm{m} / \mathrm{z}=$ $32\left(\mathrm{O}_{2}^{+}\right)$.

The uptake probability $\gamma$ is defined as the ratio of the number of collisions with the surface that lead to removal from the gas phase to the total number of collisions with the surface and is given according to Benson and Spokes (1967):

$\gamma=\frac{k_{\text {uni }}}{\omega}=\frac{k_{\text {esc }}}{\omega} \cdot\left(\frac{S_{0}}{S(t)}-1\right)$,

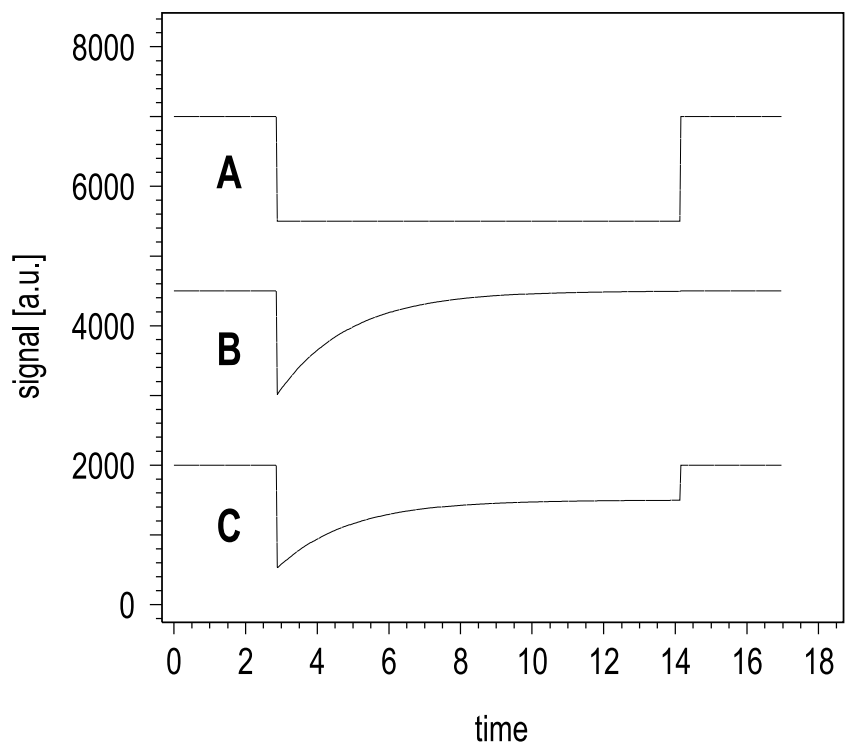

Fig. 2. Synthetic data: uptake without surface passivation (trace A); uptake with complete surface passivation (trace B); uptake with partial surface passivation (trace C). See text for details.

where $k_{u n i}$ is the pseudo-first-order rate constant, $\omega$ the collision frequency of a molecule with the reactive surface area of the sample, $k_{\text {esc }}$ the escape rate constant, $S_{0}$ the MS signal of the reactant gas prior to raising the isolation plate, and $S(t)$ the signal at time $t$ after raising the isolation plate.

\section{Results and discussion}

The Knudsen reactor technique is suited for the determination of uptake coefficients of trace gases adsorbed onto surfaces and for the observation of gas-phase products formed in heterogeneous reactions. The time dependence of the experimental uptake coefficient can take on several forms, which contain information about the nature of the gas-surface interaction. In Fig. 2, we display three synthetic data sets that describe the expected response of the measured trace gas concentration as a function of the exposure time for a trace gas interacting with a solid surface. (Traces $\mathrm{A}$ and $\mathrm{C}$ are shifted up- and downwards, respectively, relative to trace B.) In trace A, the uptake coefficient displays no dependence on time over the exposure period $(3 \mathrm{~min}<t<14 \mathrm{~min})$. Such data sets may be obtained in irreversible uptake when sufficiently low trace-gas concentrations are used, that do not appreciably modify the composition of the surface or modify the concentration of a second surface reactant at time $t$, compared to time $t_{\mathrm{open}}$. If higher trace gas concentrations are used, the time dependence of the uptake coefficient can take the form of trace B, which shows an initially large uptake coefficient that goes to zero at long exposure times. This can be explained by complete removal of reactive sites during an 

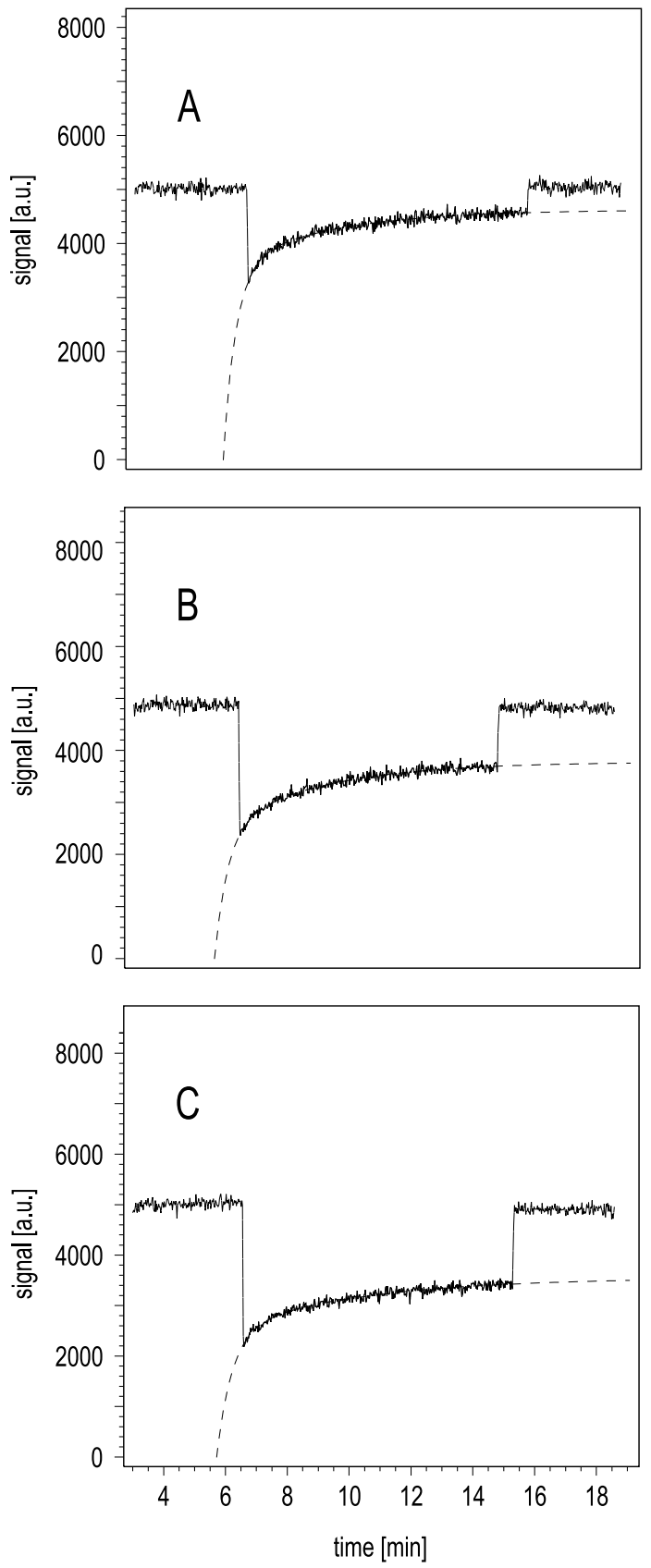

Fig. 3. Raw data showing the uptake of $\mathrm{O}_{3}\left(\mathrm{~m} / \mathrm{z}=48\right.$; $\left[\mathrm{O}_{3}\right]$ $=2.8 \times 10^{11} \mathrm{~cm}^{-3}$ ) onto $2.3 \mathrm{mg} / \mathrm{cm}^{2}$ (A), $7.6 \mathrm{mg} / \mathrm{cm}^{2}$ (B), and $14.2 \mathrm{mg} / \mathrm{cm}^{2} \mathrm{SDCV}(\mathbf{C})$; the dashed lines correspond to modified bi-exponential fits that were used for the determination of $S\left(t_{\text {open }}\right)$ and $S_{\infty}$

irreversible reactive uptake process, or by surface saturation during a reversible process at equilibrium. The time dependence will depend on the concentration of the trace gas and on the surface area of the bulk substrate available for reaction. Trace $\mathrm{C}$ displays the situation where an initially large uptake coefficient decreases over time to a constant, non-zero value at longer exposure. This form of the time dependence may be encountered when, e.g. chemically or physically different sites are available for trace-gas uptake, one of which can support irreversible, catalytic uptake and the other can be de-activated on the experimental time scale. It may also be encountered when, during reactive uptake, passivation and re-activation of surface sites takes place on a similar timescale.

For each type of data set, two distinct uptake coefficients have to be distinguished: the steady-state uptake coefficient, and the initial uptake coefficient. The initial uptake coefficient, $\gamma_{o}$, obtained immediately after opening the isolation plate at time $t_{\text {open, }}$, is the same in each example with $\gamma_{o}=0.5 k_{\text {esc }} / \omega$. In contrast, the steady-state uptake coefficient, $\gamma_{s s}$, can be a large as $\gamma_{o}$, (trace A) as low as zero (trace $\mathrm{B})$ or any number between (trace C). The analysis of C-type profiles can be complicated by surface processes, which may involve diffusion into, e.g. a porous bulk substrate, and surface re-organisation and de- and reactivation. In addition, in trace types $\mathrm{B}$ and $\mathrm{C}$ the measured initial uptake coefficient is often observed to decrease with increasing trace gas concentration (due to rapid surface passivation on the time scale of data-acquisition to obtain $\gamma_{o}$ ) or when adsorption and desorption time scales are similar. Generally, the initial uptake coefficient can only be applied to model an uptake process in the atmosphere if the concentration of the respective trace gas is low enough (and the number of reactive sites is high enough) for surface passivation to be negligible over a period of several hours, i.e. over the lifetime of dust in the atmosphere.

In the present experiments the data was generally of the form given in trace $\mathrm{C}$, and the uptake process is characterised by both an initial and a steady-state uptake coefficient. The use of atmospherically relevant $\mathrm{O}_{3}$ concentrations was therefore an important consideration in this work, as uncertainties regarding extrapolation of results to the situation in the atmosphere can be reduced.

\subsection{The uptake coefficient for $\mathrm{O}_{3}$ onto SDCV}

Most experiments were performed using samples with the dust being dispersed onto the support with ethanol. For a few samples water was used instead of ethanol; within the limit of uncertainty no difference in the uptake coefficients could be observed.

\subsubsection{Dependence on sample mass and $\mathrm{O}_{3}$ flow}

Raw data showing the uptake of $\mathrm{O}_{3}$ onto SDCV at three different sample masses $\left(2.3,7.6\right.$, and $\left.14.2 \mathrm{mg} / \mathrm{cm}^{2}\right)$ are presented in Fig. 3. The MS signal at $m / z=48$ corresponded to an $\mathrm{O}_{3}$ concentration of $\left[\mathrm{O}_{3}\right]=2.8 \times 10^{11} \mathrm{~cm}^{-3}$. When the isolation plate was open $(6.5 \mathrm{~min}<t<15.5 \mathrm{~min})$, a clear reduction in signal intensity at $m / z=48$ was detected. From the difference in signal intensity at $m / z=48$ before and 
after opening the isolation plate at $t_{\text {open }}$ an initial uptake coefficient, $\gamma_{o}^{\text {geom }}$, can be calculated according to Eq. (1). The superscript "geom" signifies that the uptake coefficient was calculated using the geometric surface area $A^{\text {geom }}$ of the sample. The three panels of Fig. 3 demonstrate that the amount of $\mathrm{O}_{3}$ taken up by the dust sample for a given exposure period is dependent on the sample mass. For the experiments shown in Fig. 3 the following initial uptake coefficients have been determined: $\mathrm{A}\left(2.3 \mathrm{mg} / \mathrm{cm}^{2}\right): \gamma_{o}^{\text {geom }}=0.5 \times 10^{-2}, \mathrm{~B}$ $\left(7.6 \mathrm{mg} / \mathrm{cm}^{2}\right): \gamma_{o}^{\text {geom }}=1.0 \times 10^{-2}$, and C $\left(14.2 \mathrm{mg} / \mathrm{cm}^{2}\right)$ : $\gamma_{o}^{\text {geom }}=1.3 \times 10^{-2} \cdot \gamma_{o}^{\text {geom }}$ clearly increases with increasing sample mass.

Similarly, a steady-state uptake coefficient $\gamma_{s s}^{\text {geom }}$ can be calculated from the asymptote $S_{\infty}$ of a modified biexponential fit to the data during exposure:

$$
\begin{aligned}
& S(t)=S_{\infty}-a_{1} \exp \left(-k_{1}\left(t-t_{\text {open }}\right)\right) \\
& -a_{2} \exp \left(-k_{2}\left(t-t_{\text {open }}\right)\right) .
\end{aligned}
$$

This expression has no physical basis, but allows us to extract precise values (statistical errors of about $1 \%$ ) of $\mathrm{S}_{\infty}$. We note that the difference between values of $S_{\infty}$ derived by fitting compared to those obtained by visual inspection were about $10 \%$. Similar to $\gamma_{o}^{\text {geom }}, \gamma_{s s}^{\text {geom }}$ increases with increasing sample mass $\left(\mathrm{A}: \gamma_{s s}^{\text {geom }}=0.9 \times 10^{-3}, \mathrm{~B}: \gamma_{s s}^{\text {geom }}=\right.$ $3.1 \times 10^{-3}$, and $\left.\mathrm{C}: \gamma_{s s}^{\text {geom }}=4.5 \times 10^{-3}\right)$. At this $\mathrm{O}_{3}$ concentration $\left(\left[\mathrm{O}_{3}\right]=2.8 \times 10^{11} \mathrm{~cm}^{-3}\right)$, initial uptake coefficients are bigger than steady-state uptake coefficients by a factor 3-5.

The phenomenon of geometric uptake coefficients being dependent on sample mass is frequently observed for the interaction of trace gases with porous bulk substrates and is due to diffusion of molecules into interstitial space. This results in an overestimation of the uptake coefficient if $A^{\text {geom }}$ is used to calculate it. Keyser and co-workers have developed a model for ice surfaces (Keyser and Leu, 1991, 1993) which in principle can also be applied to granular surfaces (e.g. Timonen et al., 1994; Leu et al., 1995). This model predicts a linear dependence of the uptake coefficient on the sample mass if the sample height is much less than the diffusion depth of the gas molecules into the bulk sample. The dependence becomes weaker as the thickness of the bulk sample becomes larger than the diffusion depth of the gas molecules, and eventually reaches a plateau. This model can be used to extract the "true" uptake coefficient from the one based on the geometric surface area. Once corrected for pore diffusion, the uptake coefficient $\gamma^{p d}$ can be considerably smaller than that based on the geometrical surface area, $\gamma^{\text {geom }}$. The two uptake coefficients are related to each other by:

$\gamma^{\mathrm{geom}}=\gamma^{p d} \rho_{b} A^{B E T} \bar{d}\left(\frac{1}{2}+\eta\left(\frac{h}{\bar{d}}-\frac{1}{2}\right)\right)$,
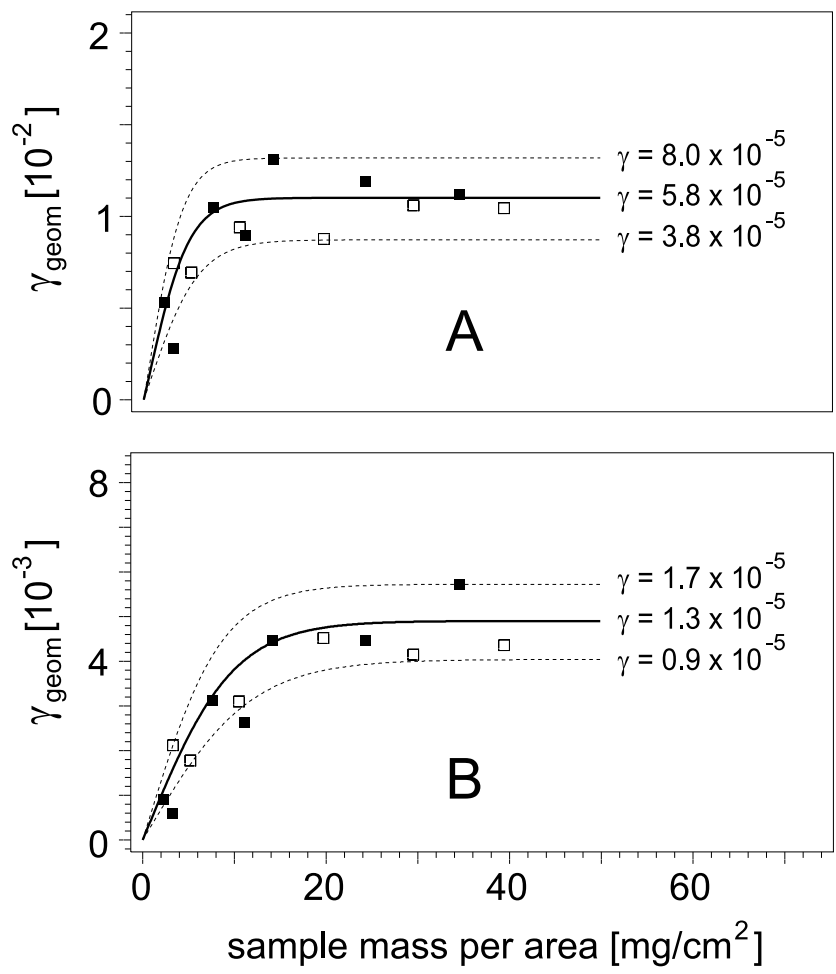

Fig. 4. Plot of geometric uptake coefficients of $\mathrm{O}_{3}\left(\left[\mathrm{O}_{3}\right]=\right.$ $2.8 \times 10^{11} \mathrm{~cm}^{-3}$ ) on SDCV versus normalised sample mass: (A) initial uptake coefficients $\gamma_{o}$, (B) steady-state uptake coefficients $\gamma_{s s}$. Filled symbols represent experiments with ethanol dispersed samples, open symbols experiments with water dispersed samples. The data have been fitted by the pore diffusion model (central solid lines; the dashed lines give the range of uncertainty).

where $\eta$ is the "effectiveness" factor, $\eta=\frac{\tan \phi}{\phi}$, and $\phi$ is the Thiele modulus whereby:

$\phi=\left(\frac{h}{\bar{d}}-\frac{1}{2}\right)\left(\frac{3 \rho_{b}}{2\left(\rho_{t}-\rho_{b}\right)}\right) \sqrt{3 \tau \gamma^{p d}}$.

The input parameters for the calculation of the pore diffusion-corrected uptake coefficient $\gamma^{p d}$ of $\mathrm{O}_{3}$ onto SDCV are: the geometric uptake coefficient $\gamma^{\text {geom }}$, the total height of the sample $h$, the average grain size of the particles $(\bar{d}$ $=0.9 \mu \mathrm{m})$, the true density $\rho_{t}\left(=2.7 \mathrm{~g} / \mathrm{cm}^{3}\right)$, the bulk density $\rho_{b}\left(=1.2 \mathrm{~g} / \mathrm{cm}^{3}\right)$, the specific BET surface area $A^{B E T}$ $\left(=39.6 \mathrm{~m}^{2} / \mathrm{g}\right)$ and the tortuosity factor $\tau$, which may be regarded as a measure of hindrance to diffusive mass transfer into the pores of the sample, and which will depend on physical characteristics of both the bulk substrate and the gaseous species. Values of $\tau$ are usually empirically determined by measuring the variation of the uptake coefficient with sample mass. The sample heights, normalised to sample areas of $1 \mathrm{~cm}^{2}$, were calculated from the sample mass $m$, the bulk density $\rho_{b}$ and the surface area of the sample holder.

Figure 4 shows the results for $\gamma_{o}^{\text {geom }}$ (panel A) and $\gamma_{s s}^{\text {geom }}$ (panel B) for the complete set of experiments at $\left[\mathrm{O}_{3}\right]=$ 


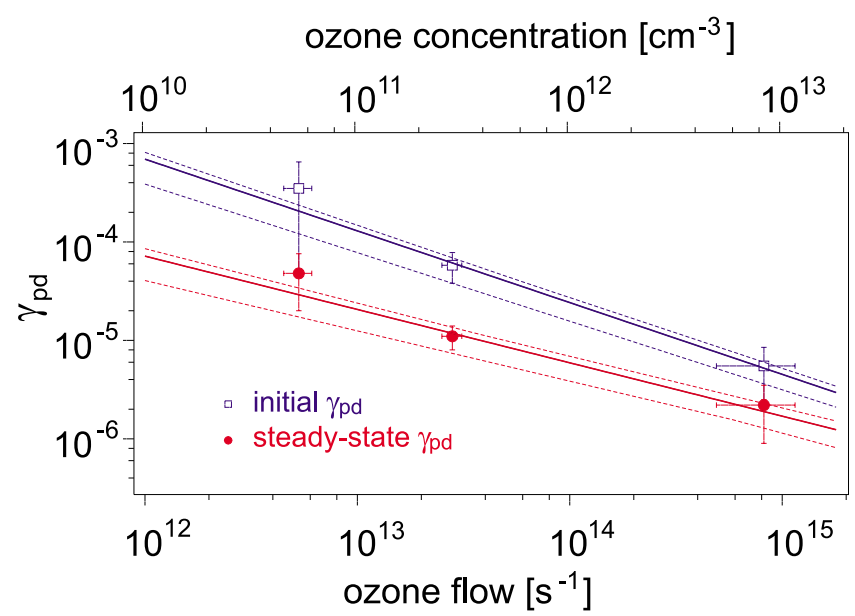

Fig. 5. Plot of pore diffusion-corrected initial and steady-state uptake coefficients of $\mathrm{O}_{3}$ on SDCV versus $\mathrm{O}_{3}$ concentration and flow, respectively. The error bars denote fluctations in the $\mathrm{O}_{3}$ concentration and the upper and lower limits of the uptake coefficients as obtained from the pore-diffusion model, respectively. The dashed lines give the $1 \sigma$-deviation from the fits.

$2.8 \times 10^{11} \mathrm{~cm}^{-3}$ (13 experiments, sample mass 2.3 to $39.4 \mathrm{mg} / \mathrm{cm}^{2}$ ). The data can be reproduced with the pore diffusion model using a tortuosity factor $\tau=1$ to yield $\gamma_{o}^{p d}=\left(5.8_{-2.0}^{+2.2}\right) \times 10^{-5}$ and $\gamma_{s s}^{p d}=(1.3 \pm 0.4) \times 10^{-5}$ (solid fit lines). The dashed lines give the upper and lower limits, respectively, within which most of the data points lie.

A further 14 experiments were carried out at $\mathrm{O}_{3}$ concentrations of $\left[\mathrm{O}_{3}\right]=(8.4 \pm 3.4) \times 10^{12} \mathrm{~cm}^{-3}$ and with varying sample mass. The results for the uptake coefficients are summarised in Table 3. The measured initial and steadystate uptake coefficients were fit according to Eqs. (3)-(4), giving as final results $\gamma_{o}^{p d}=\left(5.5_{-3.0}^{+4.0}\right) \times 10^{-6}$ and $\gamma_{s s}^{p d}=$ $\left(2.2_{-1.2}^{+1.4}\right) \times 10^{-6}$

Similarly, 15 experiments were carried out at $\mathrm{O}_{3}$ concentrations of $\left[\mathrm{O}_{3}\right]=(5.4 \pm 0.8) \times 10^{10} \mathrm{~cm}^{-3}$ and with varying sample mass. The results for the uptake coefficients are summarised in Table 4. The fits according to Eqs. (3)-(4) yielded $\gamma_{o}^{p d}=\left(3.5_{-2.5}^{+3.5}\right) \times 10^{-4}$ and $\gamma_{s s}^{p d}=\left(4.8_{-2.4}^{+3.2}\right) \times 10^{-5}$. In all cases, $\tau=1$ was used.

These results show that both $\gamma_{s s}^{\text {geom }}$ and $\gamma_{s s}^{p d}$ are smaller than $\gamma_{o}^{\text {geom }}$ and $\gamma_{o}^{p d}$, by factors $3-7$, respectively, with the biggest difference occurring for the lowest $\mathrm{O}_{3}$ flows. In Fig. 5, the pore diffusion corrected uptake coefficients (both the initial ones (open squares) and the steady-state ones (solid circles)) are plotted versus $\mathrm{O}_{3}$ concentration and flow. The solid lines in Fig. 5 are exponential functions that describe an empirical expression for the dependence of $\gamma_{o}^{p d}$ and $\gamma_{s s}^{p d}$ on $\left[\mathrm{O}_{3}\right]: \gamma^{p d}=a\left[\mathrm{O}_{3}\right]^{-b}$, where $\left[\mathrm{O}_{3}\right]$ is in $\mathrm{cm}^{-3}$. For the initial uptake coefficient we derive $a=1.48 \times 10^{4}$ and $b=0.73$, for the steady-state uptake coefficient $a=19.2$
Table 3. Uptake experiments with $\mathrm{O}_{3}$ onto $\mathrm{SDCV}$ at $\left[\mathrm{O}_{3}\right]=$ $(8.4 \pm 3.4) \times 10^{12} \mathrm{~cm}^{-3}$

\begin{tabular}{llll}
\hline$\left[\mathrm{O}_{3}\right]\left(\mathrm{cm}^{-3}\right)$ & mass $\left(\mathrm{mg} / \mathrm{cm}^{2}\right)$ & $\gamma_{o} / 10^{-3}$ & $\gamma_{s s} / 10^{-4}$ \\
\hline $9.0 \times 10^{12}$ & 4.6 & 1.3 & 0.9 \\
$1.1 \times 10^{13}$ & 5.0 & 6.9 & 0.4 \\
$1.1 \times 10^{13}$ & 10.0 & 1.4 & 0.4 \\
$9.2 \times 10^{12}$ & 10.7 & 2.4 & 1.7 \\
$1.1 \times 10^{13}$ & 15.2 & 2.7 & 1.1 \\
$4.6 \times 10^{12}$ & 17.9 & 1.6 & 0.7 \\
$1.2 \times 10^{13}$ & 25.0 & 2.0 & 1.4 \\
$6.9 \times 10^{12}$ & 26.1 & 3.9 & 1.6 \\
$1.0 \times 10^{13}$ & 30.3 & 1.7 & 1.2 \\
$6.1 \times 10^{12}$ & 33.4 & 2.4 & 1.4 \\
$1.1 \times 10^{13}$ & 40.1 & 2.9 & 2.0 \\
$9.0 \times 10^{12}$ & 42.0 & 4.3 & 2.2 \\
$1.1 \times 10^{13}$ & 45.6 & 2.6 & 1.4 \\
$9.4 \times 10^{12}$ & 51.1 & 3.2 & 1.2 \\
$\gamma_{o}^{p d}=$ & $\left(5.5_{-3.0}^{+4.0}\right) \times 10^{-6}$ & & \\
$\gamma_{s s}^{p d}=$ & $\left(2.2_{-1.2}^{+1.4}\right) \times 10^{-6}$ & & \\
\hline
\end{tabular}

Table 4. Uptake experiments with $\mathrm{O}_{3}$ onto $\mathrm{SDCV}$ at $\left[\mathrm{O}_{3}\right]=$ $(5.4 \pm 0.8) \times 10^{10} \mathrm{~cm}^{-3}$

\begin{tabular}{llll}
\hline$\left[\mathrm{O}_{3}\right]\left(\mathrm{cm}^{-3}\right)$ & mass $\left(\mathrm{mg} / \mathrm{cm}^{2}\right)$ & $\gamma_{o} / 10^{-2}$ & $\gamma_{s s} / 10^{-3}$ \\
\hline $5.4 \times 10^{10}$ & 3.2 & 1.1 & 4.6 \\
$5.0 \times 10^{10}$ & 3.3 & 1.4 & 1.9 \\
$6.1 \times 10^{10}$ & 5.1 & 1.3 & 4.1 \\
$4.7 \times 10^{10}$ & 6.3 & 2.5 & 6.5 \\
$5.5 \times 10^{10}$ & 9.8 & 3.3 & 7.6 \\
$4.7 \times 10^{10}$ & 12.3 & 5.0 & 9.2 \\
$5.2 \times 10^{10}$ & 14.5 & 1.7 & 5.0 \\
$5.3 \times 10^{10}$ & 14.9 & 2.9 & 7.7 \\
$7.4 \times 10^{10}$ & 21.6 & 2.8 & 8.0 \\
$5.1 \times 10^{10}$ & 24.7 & 2.7 & 6.9 \\
$3.9 \times 10^{10}$ & 30.3 & 1.1 & 6.0 \\
$5.1 \times 10^{10}$ & 30.6 & 5.4 & 10.0 \\
$5.4 \times 10^{10}$ & 34.9 & 2.2 & 6.3 \\
$3.3 \times 10^{10}$ & 40.6 & 2.2 & 4.5 \\
$5.9 \times 10^{10}$ & 41.1 & 4.1 & 8.9 \\
$\gamma_{o}^{p d}=$ & $\left(3.5_{-2.5}^{+3.5}\right) \times 10^{-4}$ & & \\
$\gamma_{s s}^{p d}=$ & $\left(4.8_{-2.4}^{+3.2}\right) \times 10^{-5}$ & & \\
\hline
\end{tabular}

and $b=0.54$. The exponential fits are weighted by the estimated error of $\gamma$.

A possible cause of the observed reduction in uptake coefficients as the $\mathrm{O}_{3}$ concentration was increased is rapid passivation of the surface. In order to test this, uptake of $\mathrm{O}_{3}$ 
onto $40.6 \mathrm{mg} / \mathrm{cm}^{2} \mathrm{SDCV}$ at two different $\mathrm{O}_{3}$ concentrations was investigated, as shown in Fig. 6: At $t=2.5 \mathrm{~min}$ an $\mathrm{O}_{3}$ concentration of $\left[\mathrm{O}_{3}\right]=3.6 \times 10^{10} \mathrm{~cm}^{-3}$ was established but not exposed to the dust surface. When the isolation plate was opened at $t=13 \mathrm{~min}, \mathrm{O}_{3}$ was taken up by SDCV $\left(\gamma^{\text {geom }}=2.2 \times 10^{-2}\right)$. The partial recovery of the MS signal indicated partial surface passivation, resulting in a value for $\gamma^{\text {geom }}$ of $6.3 \times 10^{-3}$ at $24 \mathrm{~min}$, shortly before the sample was isolated again. At $t=35.7 \mathrm{~min}$ the $\mathrm{O}_{3}$ concentration was increased to $\left[\mathrm{O}_{3}\right]=4.7 \times 10^{11} \mathrm{~cm}^{-3}$ and at $44.5 \mathrm{~min}<$ $t<50.8 \mathrm{~min}$, the isolation plate was again lifted leading to uptake of $\mathrm{O}_{3}$. This time an uptake coefficient was observed that decreased from $\gamma^{\text {geom }}=5.0 \times 10^{-3}(t=44.5 \mathrm{~min})$ to $3.5 \times 10^{-3}(t=50.8 \mathrm{~min})$. Finally, the $\mathrm{O}_{3}$ concentration was lowered to $3.6 \times 10^{10} \mathrm{~cm}^{-3}$ at $t=54.7 \mathrm{~min}$ and the uptake of ozone was found to be slightly enhanced with respect to the previous exposure period, with $\gamma^{\text {geom }}$ decreasing from $5.6 \times 10^{-3}(t=59 \mathrm{~min})$ to $4.6 \times 10^{-3}(t=63 \mathrm{~min})$.

From the experiment shown in Fig. 6 it can be seen that, for a given sample mass, $\gamma^{\text {geom }}$ depends not only on the degree of passivation of the sample but also directly on the $\mathrm{O}_{3}$ concentration. This explains the observation that the uptake coefficient at $59 \mathrm{~min}<t<63 \mathrm{~min}$ was larger than that at $t=50.8 \mathrm{~min}$. The enhanced availability of reaction sites at lower $\mathrm{O}_{3}$ concentrations (evidenced by the increase in $\gamma$ ) cannot be explained by reversible uptake of $\mathrm{O}_{3}$ leading to passivation, as no desorption of $\mathrm{O}_{3}$ was observed after shutting off the $\mathrm{O}_{3}$ flow. A potential explanation for the apparent enhanced reactivity at low ozone concentrations is related to the blocking of reactive sites by ozone molecules temporarily occupying neighbouring non-reactive sites. This is apparent in Fig. 6, where the reactivity is first lowered at high ozone concentrations, but increases when [ozone] is lowered again for the same dust sample. Surface sensitive studies could clarify this. We note that a comparable ozone concentration dependence for uptake to carbonaceous surfaces has been observed (Stephens et al., 1986).

3.1.2 The influence of sample heating on the uptake coefficient

Another series of experiments was conducted with SDCV samples, heated prior to the experiment, at $\left[\mathrm{O}_{3}\right] \sim 8 \times$ $10^{12} \mathrm{~cm}^{-3}$ and with varying sample mass. Geometric uptake coefficients were higher than for unheated samples by about a factor of two. The data could be fitted with the pore diffusion model using $\tau=1$. The pore diffusion corrected uptake coefficient for heated SDCV $\left(\gamma_{o}^{p d}=(1.25 \pm 0.45) \times\right.$ $10^{-5}$ ) was also higher than the one for unheated SDCV $\left(\gamma_{o}^{p d}=\left(5.5_{-3.0}^{+4.0}\right) \times 10^{-6}\right)$.

\subsubsection{Comparison with literature}

$\mathrm{O}_{3}$ uptake on Saharan sand has been investigated using a fluidised-bed reactor (Alebic-Juretic et al., 1992). Although

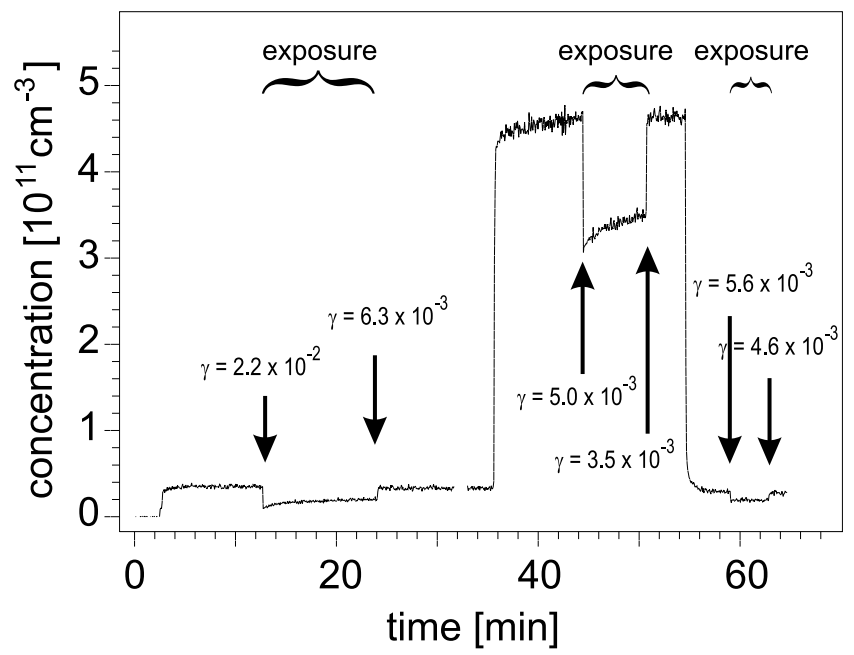

Fig. 6. Raw data showing the uptake of $\mathrm{O}_{3}(\mathrm{~m} / \mathrm{z}=48)$ onto $40.6 \mathrm{mg} / \mathrm{cm}^{2} \mathrm{SDCV}$; the $\mathrm{O}_{3}$ concentration has been changed from $3.6 \times 10^{10} \mathrm{~cm}^{-3}$ to $4.7 \times 10^{11} \mathrm{~cm}^{-3}$ (at $t=35.7 \mathrm{~min}$ ) and back again to $3.6 \times 10^{10} \mathrm{~cm}^{-3}$ (at $t=54.7 \mathrm{~min}$ ). "Exposure" indicates periods in which contact between $\mathrm{O}_{3}$ and dust took place.

uptake coefficients were not derived they can be estimated from the data presented, according to the formula:

$-\frac{d}{d t}\left[\mathrm{O}_{3}\right]=\frac{\bar{c}}{4} \gamma A_{\text {dust }}\left[\mathrm{O}_{3}\right]$

$A_{\text {dust }}$ is the surface area density of the substrate and equals the product of BET surface area of the substrate $\left(\mathrm{cm}^{2} / \mathrm{g}\right)$ and sample mass per reactor volume $\left(\mathrm{g} / \mathrm{cm}^{3}\right)$. For Saharan sand the signal reduction presented in that paper corresponds to an initial uptake coefficient of $\gamma_{o}=2.3 \times 10^{-7}$ at $\left[\mathrm{O}_{3}\right]=$ $2.5 \times 10^{12} \mathrm{~cm}^{-3}(100 \mathrm{ppbv})$. This is lower than the value extrapolated from our data by about one order of magnitude, which may be related to overestimation of the available surface area if the $\mathrm{O}_{3}$ molecules only have a limited diffusion depth into the bulk. In a similar manner, initial uptake coefficients for $\mathrm{Al}_{2} \mathrm{O}_{3}\left(\gamma_{o}=6.6 \times 10^{-9}\right)$ and calcite $\left(\gamma_{o}=4.3 \times 10^{-7}\right)$ can be calculated from the data given in that study.

An earlier study on the decomposition of $\mathrm{O}_{3}$ on $\gamma-\mathrm{Al}_{2} \mathrm{O}_{3}$ at room temperature (Klimovskii et al., 1983) reports a decomposition efficiency of $\mathrm{O}_{3}$ of $10^{-4}\left(\left[\mathrm{O}_{3}\right]=1 \times 10^{13}\right.$ to $3 \times 10^{15} \mathrm{~cm}^{-3}$ ), though it is unclear whether geometric or BET surface areas were used to derive this value. Uptake coefficients for the interaction of $\mathrm{O}_{3}$ with various types of $\mathrm{Al}_{2} \mathrm{O}_{3}$ have also been obtained from a flow-tube study at 213-473 K (Hanning-Lee et al., 1996). These authors derived pore-diffusion corrected uptake coefficients that were independent of $\mathrm{O}_{3}$ concentration $\left(5 \times 10^{15}\right.$ to $2 \times 10^{17} \mathrm{~cm}^{-3}$ ) and varied, depending on temperature, between $2 \times 10^{-11}$ and $3 \times 10^{-9}$.

A very recent Knudsen reactor study determined $\gamma_{o}=(6 \pm 3) \times 10^{-5}$ as an upper limit for $\mathrm{O}_{3}$ uptake on 


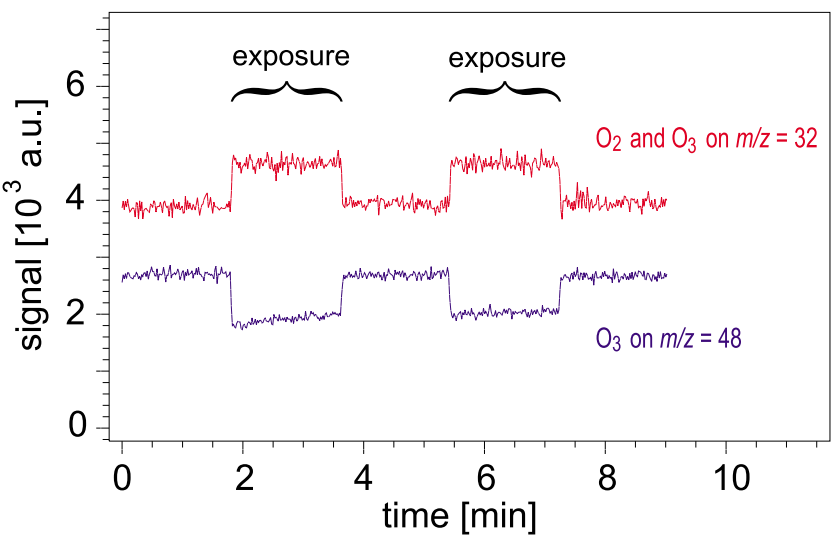

Fig. 7. Raw data showing the uptake of $\mathrm{O}_{3}\left(\mathrm{~m} / \mathrm{z}=48 ;\left[\mathrm{O}_{3}\right]=\right.$ $6.2 \times 10^{12} \mathrm{~cm}^{-3}$ ) onto $33.4 \mathrm{mg} / \mathrm{cm}^{2} \mathrm{SDCV}$, associated with release of $\mathrm{O}_{2}(\mathrm{~m} / \mathrm{z}=32)$. "Exposure" indicates periods in which contact between $\mathrm{O}_{3}$ and dust took place.

ground Saharan sand at $\left[\mathrm{O}_{3}\right]=1.9 \times 10^{11} \mathrm{~cm}^{-3}$ (Michel et al., 2002). This is in accord with the result calculated from our empirical expression for the initial uptake coefficient in Sect. 3.1.1 $\left(\gamma_{o}^{p d}=(8.6 \pm 2.0) \times 10^{-5}\right)$. Although Michel et al. (2002) observed that the uptake coefficient decreased considerably with time, no steady-state uptake coefficient was determined. Other initial uptake coefficients determined by Michel et al. (2002) for $\alpha-\mathrm{Al}_{2} \mathrm{O}_{3}, \alpha-\mathrm{Fe}_{2} \mathrm{O}_{3}, \mathrm{SiO}_{2}$, and China loess were in the range $10^{-5}$ to $10^{-4}$. In contrast to our results, no variation in the initial uptake coefficient was observed as the $\mathrm{O}_{3}$ concentration was varied between $10^{11}$ and $10^{12} \mathrm{~cm}^{-3}$.

Finally, measurements of $\mathrm{O}_{3}$ deposition velocities $\left(v_{d e p}\right)$ have been performed on various surfaces, including kaolin, sand and $\mathrm{CaCO}_{3}$ (Garland, 1974). Using these data and the formula $\gamma=4 v_{d e p} / \bar{c}$, Dentener et al. (1996) calculated uptake coefficients in the range $10^{-4}$ to $10^{-5}$. This estimate falls within the range of our results for $\mathrm{O}_{3}$ concentrations lower than about $4 \times 10^{11} \mathrm{~cm}^{-3}$ (corresponding to $16 \mathrm{ppbv}$ at STP) if the steady-state uptake coefficients are used.

Our finding that $\mathrm{O}_{3}$ uptake on heated SDCV samples is greater than on unheated samples is consistent with the observation that $\mathrm{O}_{3}$ is much more efficiently destroyed on dry soil than on moist soil (Aldaz, 1969). The same has been observed for $\mathrm{O}_{3}$ decomposition on $\gamma-\mathrm{Al}_{2} \mathrm{O}_{3}$ (Hanning-Lee et al., 1996), and on a $\mathrm{Pt} / \gamma-\mathrm{Al}_{2} \mathrm{O}_{3}$ catalyst at $50-90 \% \mathrm{RH}$ (Tsai et al., 1998). The reduced uptake can be explained by occupation of reactive sites by $\mathrm{H}_{2} \mathrm{O}$ molecules or by the complete blocking of pores (Galbally and Roy, 1980). Note that the heated samples are considered less representative of the situation in the atmosphere in which relative humidities are generally greater than $\sim 30 \%$.

\section{$3.2 \mathrm{O}_{3}$ decomposition and $\mathrm{O}_{2}$ production}

\subsubsection{Heated and unheated dust samples}

Raw data showing the uptake of $\mathrm{O}_{3}\left(\left[\mathrm{O}_{3}\right]=6.3 \times 10^{12} \mathrm{~cm}^{-3}\right)$ onto $33.4 \mathrm{mg} / \mathrm{cm}^{2}$ of heated SDCV are presented in Fig. 7 . When the isolation plate was open $(1.8 \mathrm{~min}<t<3.6 \mathrm{~min}$, and $5.4 \mathrm{~min}<t<7.2 \mathrm{~min}$ ), both uptake of $\mathrm{O}_{3}$ (reduction in signal) and an increase of the signal at $m / z=32$ are visible. Clearly, $\mathrm{O}_{3}$ is destroyed on the dust surface and $\mathrm{O}_{2}$ is produced. The $m / z=32$ signal comprised contributions both from $\mathrm{O}_{3}$ (ion fragment) and $\mathrm{O}_{2}$. Hence, for calculating the stoichiometry of the $\mathrm{O}_{3}$ to $\mathrm{O}_{2}$ conversion, the fragment pattern of $\mathrm{O}_{3}$ on $\mathrm{m} / \mathrm{z}=48$ and $\mathrm{m} / \mathrm{z}=32$ was precisely determined and used to remove the contribution of $\mathrm{O}_{3}$ to the signal at $m / z=32$. The resultant signal, due to $\mathrm{O}_{2}$ only, was converted to a flow by comparison to calibration signals.

For the analysis it was important to ensure that no significant $\mathrm{O}_{2}$ impurity was present in the $\mathrm{O}_{3}$ flow. This was achieved by comparing the sum of the $\mathrm{O}_{3}$ and $\mathrm{N}_{2}$ partial pressures, as determined by the MS, with the total Knudsen reactor pressure (capacitance manometer). (Recall that $\mathrm{O}_{3}$ is mixed into an $\mathrm{N}_{2}$ flow.) These pressures agreed to better than $2 \%$, allowing us to place a conservative upper limit of $\approx 5 \%$ to the $\mathrm{O}_{2}$ impurity in the ozone. This $\mathrm{O}_{2}$ impurity represents the main contributor to the error of the $\mathrm{O}_{3}$ to $\mathrm{O}_{2}$ conversion stoichiometry.

For the catalytic interaction of $\mathrm{O}_{3}$ with surfaces a mechanism has been proposed (Golodets, 1983) in which a terminal $\mathrm{O}$ atom of $\mathrm{O}_{3}$ binds to a surface site and results in dissociation of $\mathrm{O}_{3}$ into $\mathrm{O}_{2}$ and $\mathrm{O}$, leaving the $\mathrm{O}$ atom at the surface. The stoichiometry of this step is unity, i.e. one gas-phase $\mathrm{O}_{3}$ molecule reacts to form one $\mathrm{O}_{2}$ molecule. Surface bound $\mathrm{O}$ can further react with $\mathrm{O}_{3}$ to form two $\mathrm{O}_{2}$ molecules per $\mathrm{O}_{3}$ molecule adsorbed, or, if temperatures are high enough, two $\mathrm{O}$ atoms can migrate over the surface, meet and recombine to form an $\mathrm{O}_{2}$ molecule. In both cases, the net result is three $\mathrm{O}_{2}$ molecules formed from two $\mathrm{O}_{3}$ molecules.

In the present experiments using heated dust samples, the ratio of $\mathrm{O}_{2}$ produced to $\mathrm{O}_{3}$ taken up at steady state, i.e. after several minutes of exposure when the $\mathrm{O}_{3}$ signal remained constant, was found to be $1.30 \pm 0.05$. The difference to the theoretical stoichiometry of $1.5\left(3 \mathrm{O}_{2}\right.$ molecules released per $2 \mathrm{O}_{3}$ molecules taken up) can be explained if it is assumed that some $\mathrm{O}$ atoms remain on the surface after contact of $\mathrm{O}_{3}$ with the surface and do not form molecular oxygen that desorbs. At the beginning of the sample exposure the $\mathrm{O}_{3}$ to $\mathrm{O}_{2}$ conversion stoichiometry did change: The conversion efficiency of $\mathrm{O}_{3}$ to $\mathrm{O}_{2}$ at short exposure times was found to be just 1.2, indicating an induction period before quasi-catalytic $\mathrm{O}_{3}$ to $\mathrm{O}_{2}$ conversion starts. In the limit of zero exposure to $\mathrm{O}_{3}$ the stoichiometry cannot be greater than unity (i.e. the first $\mathrm{O}_{3}$ molecule to be taken up cannot result in release of more than one $\mathrm{O}_{2}$ ). Only with longer exposure time there is sufficient surface bound $\mathrm{O}$ which can react with a further $\mathrm{O}_{3}$ 
molecule to increase the $\mathrm{O}_{2}$ yield. Importantly, for experiments carried out using unheated dust samples the $\mathrm{O}_{3}$ to $\mathrm{O}_{2}$ conversion stoichiometry at steady-state uptake was found to be 1.0, which means that in the presence of water not only the $\mathrm{O}_{3}$ uptake coefficient but also the $\mathrm{O}_{3}$ to $\mathrm{O}_{2}$ conversion stoichiometry is reduced.

\subsubsection{The uptake mechanism}

So far, the hypothesis of Golodets (1983) has only indirectly and qualitatively been tested: The formation of $\mathrm{O}$ atoms after adsorption of $\mathrm{O}_{3}$ onto $\mathrm{TiO}_{2}$ at $77 \mathrm{~K}$ has been verified by formation of $\mathrm{CO}_{2}$ after addition of $\mathrm{CO}$ to the surface (Bulanin et al., 1995b). Also the release of $\mathrm{O}_{2}$ has been proven only indirectly, by a pressure increase during the $\mathrm{O}_{3}$ decomposition process (Hanning-Lee et al., 1996; Thomas et al., 1997), and qualitatively by the assignment of certain bonds in Raman spectra to gaseous $\mathrm{O}_{2}$ ( $\mathrm{Li}$ et al., 1998). Our determination of an $\mathrm{O}_{3}$ to $\mathrm{O}_{2}$ conversion stoichiometry of 1.3 is, to our knowledge, the first quantitative proof that Golodets' hypothesis is at least partly correct. Further, we can rule out that the $\mathrm{O}_{3}$ to $\mathrm{O}_{2}$ conversion follows a Langmuir-Hinshelwood mechanism (simultaneous adsorption of two $\mathrm{O}_{3}$ molecules at one reaction site) because such a reaction should be quadratic in $\left[\mathrm{O}_{3}\right]$, which, from Fig. 5, is clearly not the case. Therefore, $\mathrm{O}_{3}$ to $\mathrm{O}_{2}$ conversion follows an Eley-Rideal mechanism as proposed by Golodets (1983) and Li et al. (1998). Below, we explore ways to understand why not all $\mathrm{O}_{3}$ is catalytically converted to $\mathrm{O}_{2}$ and why the conversion stoichiometry is not the same for heated and unheated dust samples.

An FT-IR study (Bulanin et al., 1995a) investigated the uptake of isotopically labelled $\mathrm{O}_{3}$ onto several mineral oxides at $77 \mathrm{~K}$ and verified that $\mathrm{O}_{3}$ is adsorbed to the surface with one of its terminal $\mathrm{O}$ atoms. According to another FT-IR study of the same group on the interaction between $\mathrm{O}_{3}$ and a partially hydrated $\mathrm{TiO}_{2}$ surface (Bulanin et al., 1995b), at least three different types of surface sites for $\mathrm{O}_{3}$ adsorption can be distinguished: (I) surface sites where $\mathrm{O}_{3}$ is weakly bound to hydroxyl groups or by physisorption; (II) surface sites with weak Lewis acid character (unsaturated $\mathrm{Ti}^{\mathrm{IV}}$ ions) where $\mathrm{O}_{3}$ is chemisorbed but remains intact with distorted geometry; and (III) strong Lewis acid sites where adsorbed $\mathrm{O}_{3}$ molecules are sufficiently distorted that they dissociate into $\mathrm{O}_{2}$ and $\mathrm{O}_{2} \mathrm{O}_{3}$ adsorption to surface sites type $\mathrm{I}$ is completely reversible, as was shown for $\mathrm{O}_{3}$ adsorption onto partially hydrated $\mathrm{SiO}_{2}$ (Bulanin et al., 1994). In the present experiments, if reversible $\mathrm{O}_{3}$ uptake to $\mathrm{OH}$ groups (surface sites type I) had played a role, $\mathrm{O}_{3}$ desorption after $\mathrm{O}_{3}$ uptake should have been observable, which was not the case. Therefore, we conclude that at room temperature surface sites type I play a minor role in the uptake process.

Surface sites type II are a weak form of surface sites type III, with the strength and the number of Lewis acid sites increasing with increasing dehydration of the surface (Bulanin et al., 1995b). As type III sites are responsible for $\mathrm{O}_{3}$ destruc-

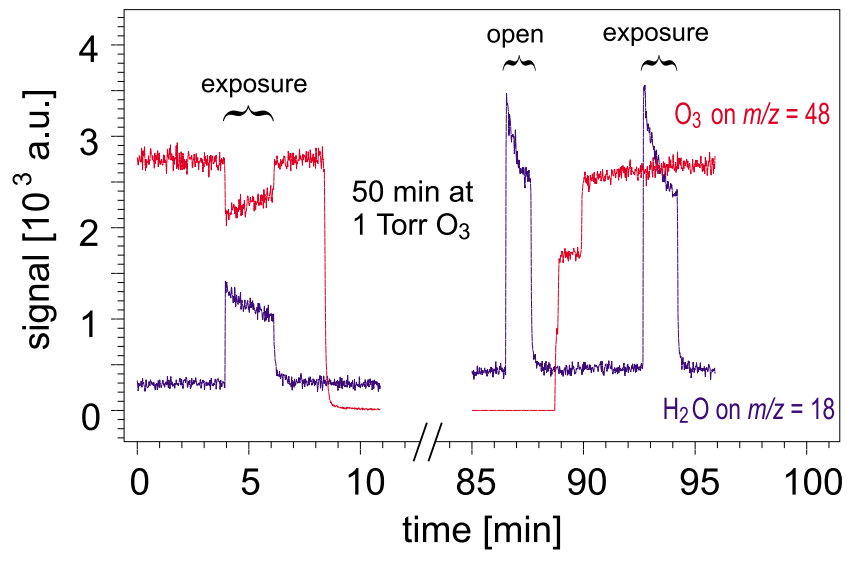

Fig. 8. Raw data showing the uptake of $\mathrm{O}_{3}\left(\mathrm{~m} / z=48 ;\left[\mathrm{O}_{3}\right]=\right.$ $3.9 \times 10^{12} \mathrm{~cm}^{-3}$ ) onto $16.4 \mathrm{mg} / \mathrm{cm}^{2} \mathrm{SDCV}$ before and after a 50 min exposure of the sample to 1 Torr of $\mathrm{O}_{3}$. While $\mathrm{O}_{3}$ uptake ceases after the exposure, water mobilisation $(m / z=18)$ is almost tripled.

tion, dehydration of the surface, i.e. by heating and evacuation should result in higher uptake coefficients and higher $\mathrm{O}_{3}$ to $\mathrm{O}_{2}$ conversion efficiencies, as observed in the present study.

Evidence for the interaction of $\mathrm{O}_{3}$ with surface hydroxyl groups was obtained in the present work whereby the release of $\mathrm{H}_{2} \mathrm{O}$ from samples exposed to $\mathrm{O}_{3}$ showed a strong, positive dependence on $\left[\mathrm{O}_{3}\right]$. The formation of $\mathrm{H}_{2} \mathrm{O}$ may be attributed to exchange of hydroxyl with oxygen species at the surface, and subsequent recombination to form water. This is exemplified in Fig. 8: The amount of water released from an $16.4 \mathrm{mg} / \mathrm{cm}^{2} \mathrm{SDCV}$ sample and detected by the MS upon opening the isolation plate is almost tripled after a $50 \mathrm{~min}$ exposure of the sample to 1 Torr of $\mathrm{O}_{3}$.

$\mathrm{O}_{3}$ decomposition on strong Lewis acid sites may take place as suggested by Golodets (1983). However, the observation of an adsorbed peroxy species after uptake of $\mathrm{O}_{3}$ to a $\mathrm{MnO}_{2}$ surface has led to the formulation of a slightly modified reaction scheme ( $\mathrm{Li}$ et al., 1998) in which the reaction of $\mathrm{O}_{3}$ with an adsorbed $\mathrm{O}$ atom does not result in the immediate desorption of two $\mathrm{O}_{2}$ molecules but only of one $\mathrm{O}_{2}$ molecule, the other one remaining adsorbed as a peroxy species and desorbing with a slower rate constant.

\subsection{Passivation of $\mathrm{O}_{3}$ uptake}

Our observations indicate that the uptake of $\mathrm{O}_{3}$ is time dependent and decreases with increased exposure time due to surface passivation. The fact that the dust surface can be passivated with respect to $\mathrm{O}_{3}$ uptake is related to the finding that the $\mathrm{O}_{3}$ to $\mathrm{O}_{2}$ conversion stoichiometry was smaller than 1.5. Catalytic $\mathrm{O}_{3}$ to $\mathrm{O}_{2}$ conversion with a stoichiometry of 1.5 would imply that no surface sites are consumed or passivated during the uptake process. A stoichiometry of 1.3 for heated dust samples and of 1.0 for unheated dust samples implies 


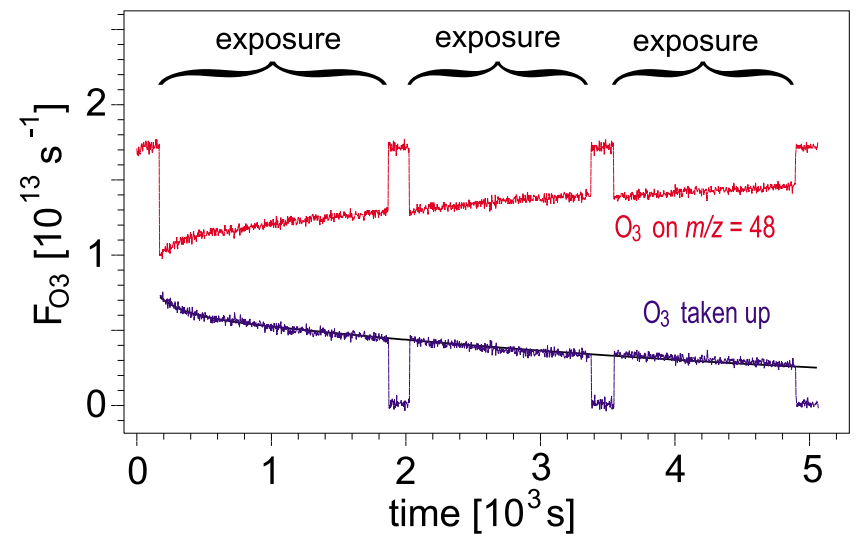

Fig. 9. Raw data showing the uptake of $\mathrm{O}_{3}(\mathrm{~m} / \mathrm{z}=48)$ onto $17.6 \mathrm{mg} / \mathrm{cm}^{2} \mathrm{SDCV}$; the $\mathrm{O}_{3}$ concentration was $1.8 \times 10^{13} \mathrm{~cm}^{-3}$ (upper curve). The lower curve shows the rate of $\mathrm{O}_{3}$ destroyed by the dust surface. The data could be fitted with a bi-exponential function.

that $\mathrm{O}$ atoms stemming from the $\mathrm{O}_{3}$ molecules must be lost to the surface.

In order to investigate passivation effects in detail, an experiment using a high $\mathrm{O}_{3}$ concentration $\left(1.8 \times 10^{13} \mathrm{~cm}^{-3}\right.$, $\sim 730 \mathrm{ppbv}$ at STP) and $17.6 \mathrm{mg} / \mathrm{cm}^{2}$ sample was carried out over an extended period of $1.3 \mathrm{~h}$. The raw data from this experiment are shown in Fig. 9 (upper curve). The (geometric) uptake coefficient decreased from an initial value of $3.3 \times 10^{-3}$ to $0.9 \times 10^{-3}$ after $1.3 \mathrm{~h}$. The number of molecules taken up by the surface could be fit by a biexponential function (Fig. 9, lower curve), although it was not possible to determine whether the uptake tends to zero or not at long exposure times. Assuming that the uptake indeed tends to zero, the total number of $\mathrm{O}_{3}$ molecules destroyed by the surface can be estimated as $2.1 \times 10^{14} \mathrm{~cm}^{-2}$. Longer exposure times could not be performed due to experimental limitations. Instead, another experiment was conducted with a similar sample mass, but with a passivation phase in which an $\mathrm{O}_{3}$ concentration of $\approx 1$ Torr $\left(\approx 3 \times 10^{16} \mathrm{~cm}^{-3}\right)$ was introduced into the reactor. The results of this experiment are depicted in Fig. 8. Prior to the passivation phase, an uptake coefficient $\gamma_{o}^{\text {geom }}=3.0 \times 10^{-3}$ was determined as usual.

Following the passivation phase no $\mathrm{O}_{3}$ uptake could be detected $\left(\gamma^{\text {geom }}<1 \times 10^{-4}\right)$ (i.e. no change in $\mathrm{m} / z=48$ at $t=92.7 \mathrm{~min})$. Following evacuation at $\sim 2 \times 10^{-6}$ Torr overnight, the sample had partially recovered and a value of $\gamma_{o}^{\text {geom }}=1.5 \times 10^{-3}$ was obtained indicating that reactivation processes have partly restored the sample reactivity overnight.

Complete passivation of the reactivity of Saharan sand was also observed in the study of Alebic-Juretic et al. (1992) who found it to be slower than passivation of calcite but much faster than passivation of $\mathrm{Al}_{2} \mathrm{O}_{3}$. This can be explained by the facts that Saharan dust is a mixture of several mineral components (Table 2), and that Lewis acid site strength decreases in the order $\mathrm{Al}_{2} \mathrm{O}_{3}>\mathrm{TiO}_{2}>\mathrm{SiO}_{2}>\mathrm{MgO}$ (Bulanin et al., 1995a; Thomas et al., 1997).

The presence of a peroxy species that is formed by reaction of $\mathrm{O}_{3}$ with a surface-adsorbed $\mathrm{O}$ atom, and which slowly decomposes and then desorbs from the surface as molecular oxygen (Li et al., 1998) would be a possible explanation for passivation if this sequence was slow enough to block reactive sites. A further explanation would be the occupation of reactive sites by atomic oxygen followed by very slow recombination on the surface and subsequent desorption of $\mathrm{O}_{2}$. A detailed investigation of the mechanism of uptake and passivation requires application of surface sensitive techniques.

\section{4 $\mathrm{O}_{3}$ uptake onto other dusts}

A few experiments were carried out at $\mathrm{O}_{3}$ concentrations of $\left[\mathrm{O}_{3}\right] \sim 6 \times 10^{12} \mathrm{~cm}^{-3}$ and using "Arizona Test Dust", Chinese dust from the Taklamakan desert, and the clay minerals kaolinite, illite, Ca-montmorillonite and palygorskite. Only initial uptake coefficients were determined, and no porediffusion corrected uptake coefficients can be given because the mass dependence of the geometric uptake coefficient was not investigated. However, the experiments were performed at high sample masses where no further variation of $\gamma^{\text {geom }}$ with increasing sample mass is expected and can thus, to a first approximation, be compared to the SDCV experiments.

For all substrates the uptake coefficients were considerably lower when unheated samples were used. For unheated kaolinite and illite, $\gamma^{\text {geom }}$ was near to or below the detection limit $\left(1 \times 10^{-4}\right)$. For Ca-montmorillonite no uptake was detected on an unheated sample $\left(\gamma^{\text {geom }}<1 \times 10^{-4}\right)$ while on a heated sample $\gamma_{o}^{\text {geom }}=3.2 \times 10^{-2}$ was found. For a heated palygorskite sample $\gamma_{o}^{\text {geom }}=2.0 \times 10^{-2}$ was determined. These results can be compared to the results for heated SDCV at $\left[\mathrm{O}_{3}\right] \sim 8 \times 10^{12} \mathrm{~cm}^{-3}$; they are higher than the results for heated SDCV by a factor of five. Interestingly, for an unheated Ca-montmorillonite sample which was prepared with ethanol $\gamma_{o}^{\text {geom }}=1.8 \times 10^{-2}$ was measured. This is in contrast to the finding that uptake onto SDCV is not sensitive to the use of ethanol instead of water.

Uptake coefficients for unheated Chinese dust and "Arizona Test Dust" were $\gamma_{o}^{\text {geom }}=3 \times 10^{-3}$ and $\gamma_{o}^{\text {geom }}=$ $2 \times 10^{-3}$, respectively. They were in the same range as $\gamma_{o}^{\text {geom }}$ for unheated SDCV (see Table 3).

\subsection{Atmospheric implications}

As pointed out by Dentener et al. (1996), the global effect of dust on $\mathrm{O}_{3}$ concentrations should be negligible if the uptake coefficient is $\gamma=10^{-5}$ and lower. The pore diffusion corrected uptake coefficient determined in this work under steady-state conditions, $\gamma_{s s}^{p d}$, for atmospheric $\mathrm{O}_{3}$ concentrations is $(7 \pm 3) \times 10^{-6}$, which is at the lower boundary of uptake coefficients used in modelling studies. In dust 
plumes particle number densities are more than two orders of magnitude higher than the background level. Taking an aerosol surface area density of $A=1.5 \times 10^{-6} \mathrm{~cm}^{2} \mathrm{~cm}^{-3}$ for a dust plume (de Reus et al., 2000) and $\gamma=10^{-5}$, the removal rate of $\mathrm{O}_{3}$ with respect to processing by dust is $k_{\text {dust }}=1.4 \times 10^{-7} \mathrm{~s}^{-1}\left(k_{\text {dust }}=\gamma \bar{c} A / 4\right)$. This has to be compared to other loss processes of $\mathrm{O}_{3}$ : photolysis with subsequent reaction of $\mathrm{O}\left({ }^{1} \mathrm{D}\right)$ with $\mathrm{H}_{2} \mathrm{O}$, reaction of $\mathrm{O}_{3}$ with $\mathrm{HO}_{2}$ and reaction of $\mathrm{O}_{3}$ with $\mathrm{OH}$ (Crutzen et al., 1999). Ozone loss due to these processes is in the same order of magnitude and only slightly higher than $\mathrm{O}_{3}$ loss by reaction on dust. Since the photochemical gas-phase loss processes are active only during the day, $\mathrm{O}_{3}$ loss by reaction on dust could be most important during night.

The preceding arguments hold if the destruction of $\mathrm{O}_{3}$ on the dust surface is catalytic without surface passivation. If, however, the surface of dust particles in the atmosphere were permanently passivated with respect to the uptake of $\mathrm{O}_{3}$, the quantification of the $\mathrm{O}_{3}$ uptake capacity of dust is important. In Sect. 3.3, a capacity of $2.1 \times 10^{14} \mathrm{O}_{3}$ molecules destroyed per $\mathrm{cm}^{2}$ of dust was calculated for SDCV. This is too low for mineral aerosol to have a noticeable effect on atmospheric $\mathrm{O}_{3}$ concentrations because, even in plumes, mineral aerosol surface areas are of the order of $10^{-6} \mathrm{~cm}^{2} \mathrm{~cm}^{-3}$. The measured bulk capacity also allows us to calculate the capacity of a single dust particle of 1 micron diameter to be approximately $1 \times 10^{7}$ molecules of $\mathrm{O}_{3}$. Combining the measured uptake coefficient of ca. $1 \times 10^{-5}$ with an ozone concentration of $40 \mathrm{ppb}$ (ca. $1 \times 10^{12} \mathrm{O}_{3} / \mathrm{cm}^{3}$ ) and a calculated collision frequency we can derive an approximate time for passivation of $100 \mathrm{~s}$. However, several observations argue against complete mineral aerosol surface passivation. Firstly, in the experiment described in Sect. 3.3 it was possible to partly restore the sample reactivity. Even if the re-activation processes are presently unknown, they should also be operating in the atmosphere, and may well be more efficient than in the dry, chemically clean Knudsen reactor environment. Note that deposition velocity measurements have shown, e.g. that exposure to $\mathrm{SO}_{2}$ rejuvenates the capacity of the surface for reaction with ozone (Garland, 1974). Secondly, the dust used in our experiments was probably transported to the Cape Verde Islands during the last ice age when dust fluxes were 15 to 30 times higher than today (Reader et al., 1999) and has been exposed to tropospheric $\mathrm{O}_{3}$ since then. In the absence of re-activation processes these dust samples would not have been reactive in our laboratory experiments.

From our experiments it is not possible to deduce a definitive uptake coefficient that can be applied to atmospheric chemistry modelling. Our laboratory observations suggest that uptake onto mineral aerosol has a negligible effect on the atmospheric ozone budget because the mineral surface is rapidly passivated. In the real atmosphere, re-activation processes may, however, compete on the same time scale as passivation, which together define the atmospherically relevant uptake coefficient for destruction of $\mathrm{O}_{3}$ on mineral dust.
Studies in environmental chambers would be most useful to elucidate this problem.

\section{Conclusions}

The heterogeneous interaction of ozone with authentic Saharan dust surfaces was investigated at room temperature. The steady-state uptake coefficient for uptake of $\mathrm{O}_{3}$ onto the mineral dust surface was determined to be $\gamma=7 \times 10^{-6}$ at tropospheric $\mathrm{O}_{3}$ concentrations. $\mathrm{O}_{3}$ was destroyed on the (unheated) dust surface and $\mathrm{O}_{2}$ was produced with a conversion stoichiometry of 1.0. The sample surface could be completely passivated by extended sample exposure to high $\mathrm{O}_{3}$ concentrations, but sample reactivity could be partially restored overnight.

Acknowledgement. We gratefully acknowledge L. Gomes for supplying the Cape Verde loess sample and D. Levi (Du Pont) for provision of the FEP 121-A Teflon suspension used to coat the Knudsen reactor. We acknowledge financial support from the European Union (ENV5-CT99-00003, MINATROC). This work was also carried out as part of a collaboration with the German-Israeli Foundation for Scientific Research and Development (I 156-303.06/97).

\section{References}

Aldaz, L.: Flux Measurements of atmospheric ozone over land and water, J. Geophys. Res., 74, 6943-6946, 1969.

Alebic-Juretic, A., Cvitaš, T., and Klasinc, L.: Ozone destruction on powders, Ber. Bunsen Ges. Phys. Chem., 96, 493-495, 1992.

Alebic-Juretic, A., Cvitaš, T., and Klasinc, L.: Kinetics of heterogeneous ozone reactions, Chemosphere, 41, 667-670, 2000.

Benson, S. W. and Spokes, G. N.: Very low-pressure pyrolysis. I. Kinetic studies of homogeneous reactions at molecular level, J. Am. Chem. Soc., 89, 2525-2532, 1967.

Berlier, G., Yamamoto, T., Spoto, G., Lamberti, C., Gribov, E., and Zecchina, A.: IR spectra of ozone adsorbed on MgO, Phys. Chem. Chem. Phys., 4, 3872-3875, 2002.

Bulanin, K. M., Alexeev, A. V., Bystrov, D. S., Lavalley, J. C., and Tsyganenko, A. A.: IR study of ozone adsorption $\mathrm{On} \mathrm{SiO}_{2}$, J. Phys. Chem., 98, 5100-5103, 1994.

Bulanin, K. M., Lavalley, J. C., and Tsyganenko, A. A.: IR spectra of adsorbed ozone, Colloid Surf. A-Physicochem. Eng. Asp., 101, 153-158, 1995a.

Bulanin, K. M., Lavalley, J. C., and Tsyganenko, A. A.: Infrared study of ozone Adsorption on $\mathrm{TiO}_{2}$ (Anatase), J. Phys. Chem., 99, 10 294-10 298, 1995b.

Bulanin, K. M., Lavalley, J. C., and Tsyganenko, A. A.: Infrared study of ozone adsorption on CaO, J. Phys. Chem. B, 101, 29172922, 1997.

Carmichael, G. R., Zhang, Y., Chen, L.-L., Hong, M.-S., and Ueda, H.: Seasonal variation of aerosol composition at Cheju island, Korea, Atmos. Environ., 30, 2407-2416, 1996.

Crutzen, P. J., Lawrence, M. G., and Pöschl, U.: On the background photochemistry of tropospheric ozone, Tellus, 51A-B, 123-146, 1999. 
de Reus, M., Dentener, F., Thomas, A., Borrmann, S., Strom, J., and Lelieveld, J.: Airborne observations of dust aerosol over the North Atlantic Ocean during ACE 2: Indications for heterogeneous ozone destruction, J. Geophys. Res., 105, 15 263-15 275, 2000.

Dentener, F. J., Carmichael, G. R., Zhang, Y., Lelieveld, J., and Crutzen, P. J.: Role of mineral aerosol as a reactive surface in the global troposphere, J. Geophys. Res., 101, 22 869-22 889, 1996.

Dhandapani, B. and Oyama, S. T.: Gas phase ozone decomposition catalysts, Appl. Catal. B-Environ., 11, 129-166, 1997.

Duce, R. A., Unni, C. K., Ray, B. J., Prospero, J. M., and Merrill, J. T.: Long-range atmospheric transport of soil dust from Asia to the Tropical North Pacific: Temporal Variability, Science, 209, 1522-1524, 1980.

Galbally, I. E. and Roy, C. R.: Destruction of ozone at the Earths surface, Q. J. Roy. Met. Soc., 106, 599-620, 1980.

Garland, J. A.: Dry deposition of $\mathrm{SO}_{2}$ and other gases, in Atmospheric surface exchange of particulate and gaseous pollutants, pp. 212-226, US ERDA symposium series, Richland, Washington, USA, 1974.

Gillette, D. A.: A qualitative geophysical explanation for hot spot dust emitting source regions, Contr. Atmos. Phys., 72, 67-77, 1999.

Ginoux, P., Chin, M., Tegen, I., Prospero, J. M., Holben, B., Dubovik, O., and Lin, S. J.: Sources and distributions of dust aerosols simulated with the GOCART model, J. Geophys. Res., 106, 20 255-20273, 2001.

Golodets, G. I.: Heterogeneous catalytic reactions involving molecular oxygen, Elsevier, Amsterdam, 1983.

Hanisch, F. and Crowley, J. N.: The heterogeneous reactivity of gaseous nitric acid on authentic mineral dust samples, and on individual mineral and clay mineral components, Phys. Chem. Chem. Phys., 3, 2474-2482, 2001.

Hanning-Lee, M. A., Brady, B. B., Martin, L. R., and Syage, J. A.: Ozone decomposition on alumina: Implications for solid rocket motor exhaust, Geophys. Res. Lett., 23, 1961-1964, 1996.

Husar, R. B., Prospero, J. M., and Stowe, L. L.: Characterization of tropospheric aerosols over the oceans with the NOAA advanced very high resolution radiometer optical thickness operational product, J. Geophys. Res., 102, 16 889-16 909, 1997.

Keyser, L. F., Moore, S. B., and Leu, M.-T.: Surface reaction and pore diffusion in flow-tube reactors, J. Phys. Chem., 95, 54965502, 1991.

Keyser, L. F., Leu, M.-T., and Moore, S. B.: Comment on porosities of ice films used to simulate stratospheric cloud surfaces, J. Phys. Chem., 97, 2800-2801, 1993.

Klimovskii, A. O., Bavin, A. V., Tkalich, V. S., and Lisachenko, A. A.: Interaction of ozone with $\gamma-\mathrm{Al}_{2} \mathrm{O}_{3}$ surface, React. Kinet. Catal. Lett., 23, 95-98, 1983.

Leu, M.-T., Timonen R. S., and Keyser, L. F.: Heterogeneous reactions of $\mathrm{HNO}_{3}(\mathrm{~g})+\mathrm{NaCl}(\mathrm{s}) \rightarrow \mathrm{HCl}(\mathrm{g})+\mathrm{NaNO}_{3}(\mathrm{~s})$ and $\mathrm{N}_{2} \mathrm{O}_{5}(\mathrm{~g})+\mathrm{NaCl}(\mathrm{s}) \rightarrow \mathrm{ClNO}_{2}(\mathrm{~g})+\mathrm{NaNO}_{3}$ (s), J. Phys. Chem., 99, 13 203-13 212, 1995.

Li, W., Gibbs, G. V., and Oyama, S. T.: Mechanism of ozone decomposition on a manganese oxide catalyst. I. In situ Raman spectroscopy and ab initio molecular orbital calculations, J. Am. Chem. Soc., 120, 9041-9046, 1998.

Michel, A. E., Usher, C. R., and Grassian, V. H.: Heterogeneous and catalytic uptake of ozone on mineral oxides and dusts: A Knudsen cell investigation, Geophys. Res. Lett., 29, 14.10.1029/2002GL014896, 2002.

Okada, K., Naruse, H., Tanaka, T., Nemoto, O., Iwasaka, Y., Wu, P.M., Ono, A., Duce, R. A., Uematsu, M., and Merrill, J. T.: X-ray spectrometry of individual Asian dust-storm particles over the Japanese islands and the north Pacific ocean, Atmos. Environ., 24A, 1369-1378, 1990.

Ouederni, A., Limvorapituk, Q., Bes, R., and Mora, J. C.: Ozone decomposition on glass and silica, Ozone-Sci. Eng., 18, 385416, 1996.

Prospero, J. M., Glaccum, R. A., and Nees, R. T.: Atmospheric transport of soil dust from Africa to South America, Nature, 289, 570-572, 1981.

Prospero, J. M. and Savoie, D. L.: Effect of continental sources on nitrate concentrations over the Pacific Ocean, Nature, 339, 687689, 1989.

Prospero, J. M.: Long-range transport of mineral dust in the global atmosphere: Impact of African dust on the environment of the southeastern United States, Proc. Natl. Acad. Sci. USA, 96, 3396-3403, 1999.

Reader, M. C., Fung, I., and McFarlane, N.: The mineral dust aerosol cycle during the last glacial maximum, J. Geophys. Res., 104, 9381-9398, 1999.

Savoie, D. L. and Prospero, J. M.: Particle size distribution of nitrate and sulfate in the marine atmosphere, Geophys. Res. Lett., 9, 1207-1210, 1982.

Savoie, D. L., Prospero, J. M., and Nees, R. T.: Nitrate, non-sea-salt sulfate, and mineral aerosol over the northwestern Indian Ocean, Geophys. Res. Lett., 92, 933-942, 1987.

Stephens, S., Rossi, M. J., and Golden, D.M.: The heterogeneous reaction of ozone on carbonaceous surfaces, Int. J. Chem. Kin., 18, 1133-1149, 1986.

Suzuki, S., Hori, Y., and Koga, O.: Decomposition of ozone on natural sand, Bull. Chem. Soc. Japan, 52, 3103-3104, 1979.

Thomas, K., Hoggan, P. E., Mariey, L., Lamotte, J., and Lavalley, J. C.: Experimental and theoretical study of ozone adsorption on alumina, Cat. Lett., 46, 77-82, 1997.

Timonen R. S., Chu, L. T., Leu, M.-T., and Keyser, L. F.: Heterogeneous reaction of $\mathrm{ClONO}_{2}(\mathrm{~g})+\mathrm{NaCl}(\mathrm{s}) \rightarrow \mathrm{Cl}_{2}(\mathrm{~g})+\mathrm{NaNO}_{3}(\mathrm{~s})$, J. Phys. Chem., 98, 9509-9517, 1994.

Tsai, W. T., Chang, C. Y., Jung, F. H., Chiu, C. Y., Huang, W. H., Yu, Y. H., Liou, H. T., Ku, Y., Chen, J. N., and Mao, C. F.: Catalytic decomposition of ozone in the presence of water vapor, J. Environ. Sci. Health Part A-Toxic/Hazard. Subst. Environ. Eng., 33, 1705-1717, 1998.

Zhang, Y., Sunwoo, Y., Kotamarthi, V., and Carmichael, G. R.: Photochemical oxidant processes in the presence of dust: An evaluation of the impact of dust on particulate nitrate and ozone formation, J. Appl. Met., 33, 813-824, 1994. 